\title{
The Provision of Intensive Care and High Dependency Care in the Field
}

\author{
MJ Roberts, JB Salmon, PJ Sadler
}

\begin{abstract}
The Defence Medical Services aspire to deliver, whenever possible, United Kingdom peacetime standards of care to servicemen injured on active service. This level of medical support calls for the provision of adequate critical care to the severely ill or injured. This paper discusses the role of critical care in the field and how it may be most effectively deployed.
\end{abstract}

\section{Introduction}

Over the last ten years a great deal has been written and discussed on the rapidly changing circumstances in which British troops may have to deploy. Hawley(1) discussed in detail how society's expectations have increased in terms of the survival of military casualties; certainly it will be politically unacceptable for British servicemen to die "unnecessarily" as a result of inadequate medical support. The acceptance at the highest level, now to be written into the emerging army medical doctrine, that UK peacetime standards of care must be achieved in the field wherever possible, has swept away the therapeutic minimalism prevalent in cold war planning.

Civilian peacetime standards in the UK dictate that an intensive care unit is available wherever the management of major trauma is planned and there is evidence that proactive use of intensive care resources effects outcome in the severely injured $(2,3)$. Is this a standard of care that can be translated easily into the field environment? Ryan(4), in a 1992 editorial looking forward to the $21 \mathrm{st}$ century, referred to the requirement to deploy intensive care services very far forward in order to improve survival during onward evacuation. Later Hawley included intensive care in the "triad" of casualty care along with Battlefield Advanced Trauma Life Support (BATLS) and resuscitative surgery, but implied that such facilities could only be provided in a static location due to logistic difficulties and the tactical constraints of manoeuvre warfare. This paper aims to discuss the requirement and practicality of providing critical care services in the field, particularly in forward areas.

\section{What is Critical Care}

Before discussing the role of these facilities in the field it is necessary to be clear on the terminology and definitions involved. In this paper the term 'critical care' is used to encompass both intensive and high dependency care. Intensive care (ICU) can be defined or described with reference to the type of patients treated or the level of nursing care offered. ICU care is appropriate for patients requiring functional support of two or more organs, patients requiring advanced respiratory support in particular positive pressure ventilation of the lungs and patients, with chronic impairment of one or more organs, who need support for an acute reversible failure of another organ system(5). The minimum nurse patient ratio for ICU is $1: 1$ and there must be twenty-four hour on site medical cover. High dependency care (HDU) is suitable for patients with single organ failure not including those requiring advanced respiratory support and patients who need closer monitoring than is available on a general ward. This last group is particularly significant in the field environment (vide infra). HDU patients should have 1:2 nursing. They may be in the early stages of their illness and go on to require intensive care or may be recovering and stepping down from intensive care but not yet fit for the general ward.

\section{Trauma Critical Care in Civilian Practice}

In UK civilian practice trauma patients requiring intensive care fall into two groups. Firstly there are those requiring this level of support prior to or soon after admission to hospital. These include thoracic injuries, major head injuries and patients with circulatory shock as well as those who require an extended recovery period following resuscitative surgery. This group includes many who would otherwise have died in the second peak of the trimodal distribution of deaths after injury described by Trunkey in 1983(6). A second group is made up of those patients who are suffering from the later complications of trauma, systemic inflammatory response syndrome (SIRS), septic shock, acute lung syndrome (ALS), acute renal failure (ARF) and multiple organ failure (MOF). These are patients who would otherwise appear in the third peak of trauma deaths.

How might high dependency care benefit the trauma patient? McQuillan et al reviewed the quality of pre-ICU care in 100 patients 
who were subsequently admitted to the ICU. The cohort whose pre-ICU care was judged to be sub-optimal had nearly twice the ICU and hospital mortality of those whose care was adequate(7). One of the steps suggested to rectify this situation was the expansion of HDU services in order to better manage patients earlier in the disease process and perhaps tip the balance in favour of survival without intensive care $(8,9)$. Furthermore Ridley(10) has shown that prior high dependency care can improve the condition of patients admitted to ICU. Parke et al showed that trauma patients admitted directly to ICU had a significantly greater probability of survival than those admitted to general wards(11). It is to be hoped, therefore, that high dependency care of the trauma victim may improve outcome by way of allowing optimal management of oxygen therapy, fluid resuscitation and analgesia and by careful monitoring so as to detect deterioration early.

\section{The Military Requirement for Critical Care}

How does the civilian experience translate into the field? The heightening of expectations over the last decade amongst servicemen and society as a whole has been alluded to above; there have been, however, developments in other areas that will have implications for casualty care. Clearly there have been medical and technical advances in the area of critical care that allow us to be more confident of survival in the seriously injured. The introduction of Battlefield Advanced Life Support (BATLS) into the training of all serving medical staff, nurses and medical assistants will, one hopes, have a significant effect on the short term survival of casualties who might otherwise have succumbed in the second peak of trauma deaths. However, BATLS will not in itself guarantee ultimate survival. Some patients will require urgent life saving surgery, others will require continuing intensive care for respiratory or circulatory failure etc. Another group, although not fulfiling the criteria for intensive care, will need closer observation than is available on the general ward of a field hospital or the dressing station of the medical regiment, in order to be optimally managed and thereby reduce the risk of later decline. These are of course high dependency patients.

The group of patients developing or suffering from the more severe complications of trauma referred to above and at risk of dying in the third peak cannot be ignored. Between 1991 and 1995, 257 battle casualites were managed in the ICU of Split Clinical Hospital in Croatia; 57 suffered from SIRS or septic shock of whom nearly $44 \%$ died(12). These conditions are probably inevitable in a proportion of trauma patients, despite optimal care. An interesting but rather different experience is reported by Gofrit et al(13) relating to the causes of death in Israel Defence Force soldiers during the 1982 war in Lebanon. In this series the second peak of deaths is greatly reduced by rapid retrieval and prompt resuscitation of casualties. Sepsis and multiple organ failure were eliminated from the third peak, suggesting that high quality and timely critical care can reduce the risk of these complications. However, this was a conflict in which the Israelis had air supremacy, there were few obstacles to rapid helicopter evacuation from the front line and the average time from injury to arrival in hospital was less than two hours, a figure that is unlikely to be achieved in a conflict between well matched adversaries.

Patients going on to develop SIRS or septic shock with ALS, ARF or MOF are usually fairly stable (and so transferable) in the first 24-48 hours following trauma or initial surgery, thereafter the difficulties of transfer increase. The preferred option for British casualties is to be repatriated to the UK before they deteriorate, however there will inevitably be circumstances where repatriation is delayed and facilities will be required to manage these conditions in theatre.

\section{Deployment of critical Care Facilities in the Field}

If it is desirable that effective critical care facilities be deployed on operations then the next step is to focus on the pattern of deployment. The options are a concentration of facilities in the rear in a static environment such as an airhead, deployment forward with Role 2+ surgical teams or a combination of both. The rear option has the advantage of allowing the concentration of resources including experienced intensive care personnel and technical support for equipment maintenance. Prioritisation of casualties for repatriation would be simplified by concentration at or near the airhead. The main disadvantage is that there would be a delay from time of resuscitative surgery at Role2+ to initiation of intensive care in the rear area. This is a critical time for the casualty who will almost certainly still be hypovolaemic, hypothermic and under the influence of analgesic and anaesthetic drugs. These patients require some form of intensive care immediately; a delay will worsen outcome and is not compatible with the principle of achieving peacetime standards in the field. The deployment of a critical care capability forward to Role $2+$ is one solution. Finally, there must be a link between the forward and rear elements of intensive care in order to allow safe transfer of highly dependent patients.

So what of the practical difficulties of 
providing intensive care in the austere Role 2+ environment? In early 1999 a two-table field surgical team (FST) was deployed by 23 Parachute Field Ambulance to Macedonia to provide Role 2+ surgical support to troops on Operation AGRICOLA. The initial configuration was a four bay resuscitation department, a two table operating theatre and a four bay postoperative department including one ICU bay and one HDU bay. X-ray, diagnostic ultrasound scan and simple laboratory support were included and two six-bed wards were added in due course. Deployed in DRASH tents, the core departments of this unit could be set up and open to receive casualties in ninety minutes and taken down and ready to move in three hours. No heavy lift was required for loading and unloading. Figure 1 shows the intensive care bay and its

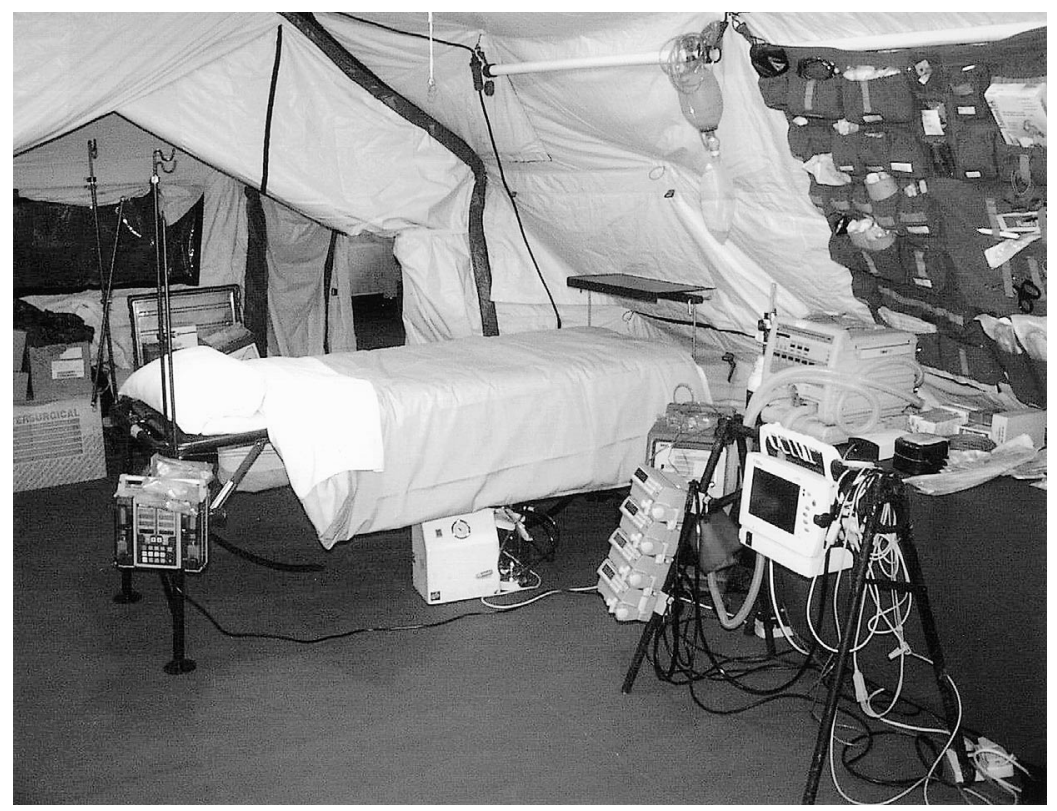

Figure 1. The Intensive Care bay deployed by the 23 Parachute Ambulance surgical team on Operation AGRICOLA.
Table 1. Some of the conditions managed in the ICU/HDU at the 23 Parachute Field Ambulance Surgical Group, Operation AGRICOLA March-fune 1999.

\begin{tabular}{ll}
\hline Diabetes Mellitus & Burns \\
Hepatorenal Failure & Chest Injury \\
Cardiac Dysrhythmia & Multiple Trauma \\
Chest Infections & Crush Syndrome \\
Chest Pain ?Cardiac & Ruptured Ectopic Pregnancy \\
Asthma & \\
\hline
\end{tabular}

improve the flexibility of Role $2+$ surgical units in manoeuvre warfare.

The level of care on general wards influences the utilisation of any critical care facility. In a Role 3 field hospital or hospital squadron with its full complement of nursing staff the standard of care on the wards is high and many casualties can be confidently transferred to the ward after recovery from anaesthesia and surgery. At the Role 2+ unit the situation is different. There are few trained nurses and many of the general nursing tasks are carried out by combat medical technicians (CMT) who have little experience of managing post operative patients. This was the situation in the early phase of Operation AGRICOLA in Macedonia; as a result many patients who had undergone emergency surgery were cared for in the ICU/HDU for at least the first post-operative night. This trend was reversed once 22 Field Hospital were deployed with its greater complement of skilled nurses (Gardiner - personal communication). Of course many patients will not be trauma or even surgical in origin. Table 1 lists some of the conditions managed on the 23 Parachute Field Ambulance HDU during Operation AGRICOLA prior to the entry into Kosovo in June 1999. Note that all these conditions presented in UK servicemen or servicewomen. Despite this the main thrust of planning will always be to achieve the most efficient distribution of assets for the management of battle casualties. To that end, it is proposed that a combination of critical care facilities forward, wherever resuscitative surgery is envisaged, and more sophisticated, static facilities in the rear would give the best results. The rear facility should ideally be at, or close to, the airhead. In addition, there must be a capability to evacuate critically ill patients from forward units. Ideally this should be performed by trained personnel coming forward from the rear hospital to retrieve patients. These retrieval teams could be modelled on the retrieval services being developed by intensive care units in the UK. The aim should be to provide a continuous corridor of critical care from initial resuscitation to a definitive intensive care unit.

\section{The Functions of Critical Care Facilities in the Field}

Table 2 and 3 list some of the functions of forward and rear critical care facilities 
Table 2. Functions of a critical care facility in forward areas (Role 2+ or 3). Casualties to be held for a maximum of 48 hours.

Further fluid resuscitation of critically ill postoperative patients Correction of body temperature

Rapid weaning from positive pressure ventilation

Preparation of ventilated patients for in-theatre evacuation

Overnight care of other postoperative patients

(Where general ward care limited)

Preparation of critical care patients for direct repatriation (Operations other than war)

Table 3. Functions of a rear critical care facility. Holding times will depend on rate of repatriation.

As at Table 2 .

Concentration of intensive care patients

Preparation and prioritisation for repatriation

Management of severe complications of illness and injury:Acute Lung Syndrome

Acute Renal Failure

Systemic Inflammatory Response Syndrome

Septic Shock

Multiple Organ Failure

Retrieval of intensive care patients from forward areas

respectively. The staffing requirements are dictated by the role. All military consultant and experienced non-consultant career grade anaesthetists are able to manage intensive care patients as would be required at Role $2+$ (Table 1) where the emphasis is on rapid recovery or preparation for transfer. It is essential, even where casualties are only to be held for short periods, that specialist ICU nurses are employed at this level, in numbers determined by the number of critical care beds. It is unreasonable to expect untrained personnel to manage very sick patients in suboptimal circumstances when this would be unworkable in the controlled environment of a NHS hospital. At the airhead, where patients are concentrated and prioritised for repatriation, a consultant trained and experienced in intensive care medicine should direct the ICU. Again ICU nurses are required in appropriate numbers and physiotherapists are essential. Staffing at this level should take into account the requirement to retrieve casualties from forward facilities and the possibility that unstable patients may have to be held here for prolonged periods whilst receiving complex organ support.

\section{The Capacity of the Critical Care System In the Field}

Table 4 identifies some of the factors that will determine how many critical care patients will need to be provided for within the system. Clearly the battle casualty estimates and the background rate of disease and nonbattle injury are the most important but the weapons of war involved and the pattern of injury will also be key. The incidence of burn injury will vary greatly depending on the type of conflict, being high in armoured operations but lower on airborne operations or operations in built up areas. The use of weapons that result in significant blast wave formation may well affect the incidence of
Table 4. Some of the factors affecting the required capacity of critical care provision in the field.

Disease and non-battle injury rates

Casualty estimates

Pattern of Injury e.g. burns, blast, biological/chemical weapons

Admissions policy i.e. ICU/HDU/Post-operative recovery?

General ward staffing levels and standards

Aeromedical repatriation capability and policy

Host nation medical facilities

acute lung injury with implications for critical care provision.

The risk of exposure to biological or chemical weapons also needs to be taken into account. The number of beds also depends on the admission policy. Are ICU patients only to be catered for or are HDU patients, inevitably the greater number, and early post-operative patients to be included? As discussed, this in turn will depend on the level of nursing care available on the general ward, which again affects the timing of discharge from HDU. The rate of repatriation to the UK is obviously a factor as is the rate of onward referral of any patients not entitled to evacuation to UK. For example it may not be possible to transfer out local civilian patients where host nation medical support has collapsed. It is suggested that computer modelling could be employed to test the impact of these and other variables on the number of critical care beds needed and the most efficient pattern of their deployment.

\section{Conclusion}

In the days of NATO planning for general war in Europe, when very large numbers of casualties were anticipated and national survival was in doubt, it was reasonable to ration resources to clearly salvageable patients. Now the political landscape over which military operations are conducted has changed, as has the potential for medicine to preserve the patient's hold on life even at its most tenuous. Since critical care can be translated successfully into the austere environment of the field hospital and even into the dressing station or equivalent, the principle of applying peace time standards demands that this should be achieved wherever possible. Clearly there will at times be tactical or logistic constraints but the limits on the level of care allowed the battle casualty should not be financial or due to lack of will.

\section{References}

1. Hawley A. Trauma Management on the Battlefield: A Modern Approach. F R Army Med Corps 1996; 142: $120-125$

2. Bishop MH, Shoemaker WC, Appel PL et al. Prospective randomized trial of survivor values of cardiac index, oxygen delivery and oxygen consumption as resuscitation endpoints in severe trauma. Fournal of Trauma 1995; 38(5): 780787.

3. Burch JM, Ortiz VB, Richardson RJ, Martin RR, Mattox KL, Jordan GL. Abbreviated laparotomy 
and planned reoperation for critically injured patients. Annals of Surgery 1992; 215(5): 476-483

4. Ryan JM. Towards the 21st Century: Provision of Battlefield Surgical Care. f R Army Med Corps 1992; 138: 6-7

5. Standards for Intensive Care Units. Intensive Care Society 1997

6. Trunkey DD. Trauma. Sci Am 1993; 249(2): 20-26

7. McQuillan P, Pilkington S, Allan A et al. Confidential inquiry into quality of care before admission to intensive care. $\mathrm{Br} \mathrm{Med} \mathcal{F} 1998 ; 318$ : 1853-1858

8. Garrard C, Young D. Suboptimal care of patients before admission to intensive care - Editorial. $B R$ Med f 1998; 318: 1841-1842

9. Van Heerden N. High Dependency Units - the answer to suboptimal care? - Editorial. Care of the
Critically Ill 1999; 15(2): 36-37

10. Dhond G, Ridley S, Palmer M. The impact of a high dependency unit on the workload of an intensive care unit. Anaesthesia 1998; 53(9): 841847

11. Parke T, Grant P, Kennedy R, Henry J. Increased survival after serious injury with early critical care. Proceedings of the Intensive Care Society, May 1997

12. Bacic A, Gluncic I. Septic Syndrome and Septic Shock in the Wounded Treated at the Split Clinical Hospital Intensive Care Unit. Military Medicine 1997; 162(5): 363-365

13. Gofrit O, Leibovici D, Shapira SC et al. The Trimodal Death Distribution of Trauma Victims: Military Experience from the Lebanon War. Military Medicine 1997; 162(1): 24-26 